\title{
Effect of Sublethal X-irradiation on Follicular Trapping of Immune Complexes in the Mouse Lymph Node
}

By

\author{
Dong CHEN*, Hajime HOSHI, Kiyoshi TANAKA, Kaeko HORIE, \\ Shin-ichi NEGISHI, Ei-ichi SASAMOTO and Atsuko MURAKAMI \\ *Department of Histology and Embryology, Norman Bethune University of Medical Sciences, Changchun, P.R. China; \\ and Department of Anatomy, Nihon University School of Medicine, Tokyo, Japan
}

- Received for Publication, September 6, 1997 -

Key Words: Immune complex trapping, Follicular dendritic cells (FDC), Lymphoid follicles. X-irradiation, Lymph node, Mouse

\begin{abstract}
Summary: In one set of experiments, the effect of sublethal X-irradiation on the $24 \mathrm{~h}$ localization of subcutaneously injected immune complexes in the lymph node follicles was studied in mice which were given HRP-anti-HRP complexes into the rear footpad at 1-3 weeks after irradiation and killed 1 day later. The 24 h follicular localization of injected immune complexes in draining popliteal nodes was severely impaired at 7 days after irradiation, at which time residual follicles were markedly depleted of B lymphocytes. In following weeks, residual follicles began to be repopulated, and the $24 \mathrm{~h}$ follicular localization of immune complexes became restored. Follicular dendritic cells (FDC), as was detected by the in vitro trapping assay and/or by the immunostaining for complement receptors CR1, were present in lymph nodes at any time after irradiation. Another group of mice were given HRP-anti-HRP complexes at 6 days of $X$-irradiation and killed from $15 \mathrm{~min}$ to $24 \mathrm{~h}$ later. Following the injection, complexes localized in residual follicles in draining nodes within 15 min but soon diminished in density and finally disappeared by $24 \mathrm{~h}$ after injection. It is obvious that sublethal irradiation affect neither transport of immune complexes to lymph node follicles nor their localization in these follicles. Rather rapid disappearance after temporal localization of immune complexes in residual follicles in irradiated mice indicates that persisting FDC were unable effectively to trap immune complexes which were transported and localized in residual follicles. Ineffective trapping by FDC of immune complexes temporally localized in residual follicles is discussed in relation to the depletion of follicular B lymphocytes due to X-irradiation.
\end{abstract}

It is widely accepted that follicular dendritic cells (FDC) constitute the microenvironment of lymphoid follicles. FDC have the characteristic capacity to trap antigen in the form of immune complexes and retain them for long periods of time (Klaus et al., 1980). The follicular localization of immune complexes in vivo can be distinguished into two phases: first, trapping, and then retaining (Groeneveld et al., 1983). The first phase includes the process through which immune complexes are transported from the entrance site to lymphoid follicles; the retaining phase involves complement factor $\mathrm{C} 3$ and complement- and/or Fc-receptors expressed on the cell surface of FDC (Klaus and Humphrey, 1977; Gray et al., 1984; Radoux et al., 1985; Yoshida et al., 1993).

The detailed mechanism by which immune com- plexes are transported to FDC remains to be clarified. Different explanations, however, have been proposed. One is that B lymphocytes in the marginal zone mediate the transport of immune complexes to FDC in the spleen (Brown et al., 1973; Veerman and van Rooijen, 1975; Gray et al., 1984; Kroese et al., 1986), The second is that since macrophages are known to retain a small part of antigen on their surface while ingesting and degrading a large part of antigen they take up (Unanue, 1984), macrophages migrating into the follicle may work as the carrier of antigen (White et ah, 1970), and this type of antigen transport is sometimes called the "classical antigen pathway". The third possible mechanism is that immune complexes are transported from the subcapsular sinus to the periphery of germinal center by a special population

Offprint requests to: Dr. Hajime Hoshi, Department of Anatomy, Nihon University School of Medicine, Ohyaguchi, Itabashi-ku, Tokyo 173, Japan.

This research was supported by grant from the Japanese Ministry of Education, Culture and Science. 
of nonphagocytic cells in lymph nodes, and this pathway is thought to be the "alternative antigen pathway" (Tew et al., 1989). Szakal et al. (1983) considered these nonphagocytic cells as antigen transporting cells (ATC) and at the same time precursors of FDC. The other is that antigen may diffuse passively in the parenchyma along the reticular fiber network to reach the follicle (Saint-Marie and Peng, 1986; kamperdijk et al., 1987; Laman et al., 1990).

It has been shown that the $24 \mathrm{~h}$ localization of intravenously administered immune complexes in spleen follicles is prevented after sublethal X-irradiation, and this has been attributed to the depletion of total lymphocytes including marginal zone B lymphocytes due to X-irradiation (Hunter et al., 1969; Nettesheim and Hanna, 1969; Humphrey et al., 1984; Kroese et al., 1986; Van den Berg et al., 1995). Our preliminary experiments showed that the $24 \mathrm{~h}$ localization of subcutaneously injected immune complex in lymphoid follicles of draining lymph nodes was severely impaired in X-irradiated mice. The present study was therefore undertaken to see whether impaired follicular trapping in the lymph node after sublethal $\mathrm{X}$-irradiation is due to damage to antigen transport or the other element(s) such as lymphocytes and/or FDC.

\section{Materials and Methods}

\section{Animals}

Eight-week-old male C57Bl/mice (Charles River Japan) were used. They were maintained under standard laboratory conditions.

\section{$X$-irradiation}

Mice were X-irradiated with $500 \mathrm{rad}(5 \mathrm{~Gy})$ delivered by a Shimazu X-ray machine, run at $180 \mathrm{kV}$, $5 \mathrm{~mA}$, at a distance of $60 \mathrm{~cm}$ with filtration of 0.5 $\mathrm{mm} \mathrm{Al}$ and $0.3 \mathrm{~mm} \mathrm{Cu}$.

\section{Necropsy and tissue processing}

For immunohistochemistry and demonstration of in vivo and in vitro follicular trapping of immune complexes, popliteal lymph nodes taken from control and irradiated mice were rapidly frozen in a dry ice-acetone mixture, and each node was serially cut into 3 or $\mathbf{4}$ series of semi-serial sections. All cryostat sections were air-dried, fixed in acetone for $10 \mathrm{~min}$ and air-dried again.

For observation of tracer substances, the obtained specimens were fixed in Zenker-formol solution for 3-4 h, dehydrated, embedded in JB-4 resin, sectioned at a thickness of $5 \mu \mathrm{m}$ and observed under the fluorescence microscope.

\section{Immune complex trapping assay in vivo}

For demonstration of follicular trapping of in vivo -applied immune complexes (Chen et al., 1978; Dijkstra et al., 1982), control and irradiated mice were each injected with $20 \mu \mathrm{l}$ of HRP-anti-HRP antibody complex solution (rabbit PAP, Dako) into the left rear footpad, and the ipsilateral popliteal nodes were obtained at scheduled intervals after the PAP injection.

One of 3-4 series of semi-serial cryostat sections prepared from each node were stained for peroxidase activity with 3,3'-diaminobenzidine tetra- $\mathrm{HCl}$ (DAB, $0.5 \mathrm{mg} / \mathrm{ml}$; Sigma Chem. Co., St. Louis, USA) in $0.05 \mathrm{M}$ Tris- $\mathrm{HCl}$ buffer ( $\mathrm{PH} 7.6$ ) containing $0.01 \% \mathrm{H}_{2} \mathrm{O}_{2}$, and counterstained with a methylgreen solution.

\section{Immune complex trapping assay in vitro}

One series of semi-serial sections of the node was used for demonstrating immune complex trapping in vitro on cryostat sections (in vitro trapping assay; van Rooijen, 1978; Dijkstra et al., 1983; Yoshida et al., 1993). Sections were incubated for $3 \mathrm{~h}$ in a medium containing the HRP-anti-HRP complex (mouse PAP, 1:20 diluted in phosphatebuffered saline (PBS); Dako Corp., Carpinteria, USA) supplemented with $20 \%$ fresh mouse serum. After washing in PBS, peroxidase activity was visualized by incubating in a solution of DAB and $\mathrm{H}_{2} \mathrm{O}_{2}$ as described above.

\section{Immunohistochemistry}

Rat anti-mouse CD45R/B220 antibody (Coffman and Weissman, 1981), 8C12, a rat antibody against mouse complement receptor CR1 (Kinoshita et al., 1988), MOMA-1, anti-mouse metallophilic macrophage (Kraal and Jause, 1986), and MOMA-2, antimouse pan-monocyte/macrophage (Breel et al., 1987), were used.

Immunostaining was performed by an indirect method, as follows. One series of cryostat sections was incubated with optimal concentrations of monoclonal antibodies in PBS containing $0.2 \%$ mouse serum. After washing three times with PBS, the sections were incubated with peroxidase-conjugated rabbit anti-rat $\lg$ (DAKO, Denmark, diluted $1: 150$ ) for $30 \mathrm{~min}$ at room temperature, and then peroxidase activity was visualized by incubating in a solution of DAB and $\mathrm{H}_{2} \mathrm{O}_{2}$.

\section{Injection of tracer}

Control mice and experimental mice at 6 days of X-irradiation were each injected with $40 \mu \mathrm{l}$ of FITC-conjugated rabbit $\mathrm{lgG}(10 \mathrm{mg}$ in $1 \mathrm{ml}$ of saline) into the rear footpad and killed 30 or $90 \mathrm{~min}$ later. 
Another control mice and experimental mice at 3 days of $X$-irradiation were injected with $20 \mu$ of Fluoresbrite beads (YG latex, $0.5 \mathrm{~mm}$ in diameter, Polysciences Inc. Warrington, USA) into the rear footpad and killed 3 days later.

\section{Results}

\section{Normal popliteal lymph node}

Normal popliteal nodes contained generally 12 lymphoid follicles with only occasional germinal centers (Fig. 1). Lymphoid follicles were observed as nodular accumulations of B220-positive lymphocytes in the peripheral cortex (Fig. 2a).

After the in vitro trapping assay, the in vitro -applied immune complexes were localized in every lymphoid follicle with a dendritic pattern of distribution (Fig. 2b). In mice which were injected with HRP-anti-HRP immune complex solution and killed $24 \mathrm{~h}$ later, complexes were seen localized in the central portion of lymphoid follicles (Fig. 2c), but some follicles of smaller size showed only faint or no localization of complexes.

24 h localization of in vivo-applied immune complexes in irradiated mice

Irradiated animals were sacrificed at 7,14 or 21 days after irradiation. Each animal was injected with HRP-anti-HRP immune complex into the left hind footpad $24 \mathrm{~h}$ prior to necropsy.

At 7 days after irradiation, popliteal nodes were extensively depleted of lymphocytes. Residual lymphoid follicles, or remnants of follicles, were observed as very small aggregates of persisting B220positive cells (Fig. 3a). We recognized approximately 8 residual follicles in each node, the number being smaller by 4 than the number of follicles in normal popliteal nodes. Follicles of smaller size in normal popliteal nodes may have been destroyed and vanished due to $\mathrm{X}$-irradiation. In sections treated with the in vitro trapping assay, in vitro -applied immune complexes were localized in residual follicles in a dendritic pattern of distribution (Fig. 3b). In sections stained for the complement receptors CR1 on the cell surface of FDC, each residual follicle displayed network of complement receptors within the structure (Fig. 3c). At this stage, the $24 \mathrm{~h}$ localization of in vivo -injected immune complexes was scarcely recognized in any residual follicles (Fig. 3d).

At day 14, B lymphocytes were slightly increased in number in each residual follicle, and by day 21 residual follicles were fairly well repopulated. At day 14, in vivo -applied immune complexes were found to localize in only some of the residual fol- licles, but at day 21 most follicles displayed the $24 \mathrm{~h}$ localization of injected immune complexes (Fig. 1).

\section{Earlier folliclular localization of in vivo-applied immune complexes}

Non-irrdiated control mice and irradiated mice at 6 days of irradiation were each injected with HRP-anti-HRP complexes solution into the rear footpad and sacrificed 15, $90 \mathrm{~min}, 3$ and $24 \mathrm{~h}$ later.

In control mice, at 15 min after injection macrophages bordering the subcapsular sinuses were strongly positive for peroxidase activity, having been interiorizing immune complexes. Such macrophages were numerous in the medullary region. A small amount of immune complexes was observable within some follicles, displaying a fine reticular and dendritic pattern of distribution. As time going on, follicles displaying network of complexes increased in number, and at $24 \mathrm{~h}$ after injection most follicles showed localization of complexes in the central portion of the structure (Fig. 2).

At the 6-7 day stage after $X$-irradiation, residual follicles in popliteal nodes were very small, lymphocytes having been remarkably reduced in number, and sometimes hard to recognize. In this study, therefore, each residual follicle was identified by way of comparative three-dimentional observation of two or three semi-serial sections from each node which were stained for B220-positive lymphocytes and for either complement receptors (CR1) or in vitro trapped immune complexes or both. In these sections, residual follicles were recognized as small aggregate of B220-positive cells and as network of either complement receptors or in vitro trapped immune complexes (Figs. 5a and 5b)

At $15 \mathrm{~min}$ after the immune complex-injection into irradiated mice, complexes were observable within all detectable residual follicles as network of irregular strands (Fig. 5c). Thereafter, however, complexes localized in residual follicles diminished and disappeared by $24 \mathrm{~h}$ after injection (Fig. 6).

\section{Distribution of tracer}

Normal mice and experimental mice at $6 \mathrm{~d}$ of $\mathrm{X}$ irradiation were injected with FITC-conjugated lgG into the rear footpad and killed 15 or 90 min later.

In normal mice, at $15 \mathrm{~min}$ tracer was distributed in the subcapsular sinus and throughout the nodal parenchyma. In the latter, tracer was seen preferentially along the reticular fibers in the parenchyma and at the basement membrane of small blood vessels. Tracer was rather scanty in the follicular region. At $90 \mathrm{~min}$, tracer became decreased in density in the subcapsular sinus and the peripheral cortex but remained dense in the medulla and deeper portion of the cortex. 
The distribution pattern of tracer in the popliteal nodes of irradiated mice at 15 and 90 min after injection was similar to that in control mice at the corresponding stage. No increased or decreased localization of tracer in residual lymphoid follicles was noted in irradiated mice (the data not shown).

Normal mice and experimental mice at $3 \mathrm{~d}$ of $\mathrm{X}$ irradiation were injected with YG latex into the rear foot pad and killed $3 \mathrm{~d}$ later.

In irradiated as well as normal mice, macrophages interiorizing YG latex migrated from the injected site were seen in the subcapsular sinus, scattered in the deep cortex and frequent in the medulla.

\section{Distribution of MOMA-1- and MOMA-2-positive macrophages}

In normal mice, MOMA-1-positive macrophages bordered the subcapsular sinus and were frequent in number in the medulla. MOMA-2-positive macrophages bordered the subcapsular sinus, were numerous in the medulla and scattered throughout the deep cortex but rather few in the follicular region.

The distribution pattern of MOMA-1- and MOMA-2-positive macrophages in popliteal nodes at $6 \mathrm{~d}$ after $\mathrm{X}$-irradiation was similar to the case of normal mice, except that medullary macrophages were much fewer in irradiated mice than in normal control.

\section{Discussion}

The present study showed that in irradiated mice, the $24 \mathrm{~h}$ localization of subcutaneously administered (HRP-anti-HRP) immune complexes in lymph node follicles was severely impaired at around 6 days after sublethal $\mathrm{X}$-irradiation but restored in following weeks as residual follicles, or remnants of follicles, depleted of B lymphocytes due to irradiation began to be repopulated. Following the injection of immune complexes at 6 days of X-irradiation, complexes localized in residual follicles of draining lymph nodes within $15 \mathrm{~min}$, but localized complexes soon diminished and disappeared from residual follicles by $24 \mathrm{~h}$ after injection. It is obvious that $\mathrm{X}$-irradiation did not affect transport of immune complexes from the subcapsular sinus to the follicle but instead impaired the retention phase of immune complex trapping. The present results form sharp contrast to the case of the spleen where abolishment of the $24 \mathrm{~h}$ follicular localization of immune complexes following (sub)lethal $\mathrm{X}$-irradiation has been shown to be due to marked depletion of marginal zone $B$ lymphocytes which mediate the transport of immune complexes from the marginal zone to the follicle center (Brown et al., 1973; Veerman and Rooijen, 1975; Gray et al., 1984; Kroese et al., 1986).

Following $\mathrm{X}$-irradiation, lymphocytes are extensively destroyed throughout the body, radioresistant FDC and a very small number of B lymphocytes being left behind in each residual follicle in the lymphoid organs (Kinet-Denoël et al., 1982; Humphrey et al., 1984; Hoshi et al., 1984; Chen et al., 1995). In this study, therefore, 3-4 semi-serial sections were prepared from each popliteal node taken from irradiated mice, and 2-3 semi-serial sections were stained for persisting FDC and B lymphocytes: the presence of peristing FDC in residual follicles was assesed either by the demonstration of complement receptors, CR1, or by the in vitro trapping assay, or both. In such stained sections, residual follicles were observed as small aggregates of persisting B220-positive cells and as either network of in vitro -trapped IC and/or network of complement receptors.

It has been shown that the in vivo follicular trapping of immune complexes (IC) requires complement factor, C3, and localized IC take form of IC-complement complexes, or more precisely C3IC complexes (Klaus and Humphrey, 1977; Gray et al., 1984; Radoux et al., 1985; Van den Berg et al., 1992). Localized C3-IC are then believed to be rapidly trapped by FDC, by way of binding to complement receptors (CR1 and CR1/2 in mice) on the cytoplasmic projections of FDC (Yoshida et al., 1993; Van den Berg et al., 1995). Once localized in lymphoid follicles, IC are known to be retained there for long periods of time. In this study, IC in soluble form were injected into irradiated mice and were found to localize in residual follicles of draining lymph nodes as early as $15 \mathrm{~min}$ after injection. Possibly, injected soluble IC may have localized there in the form of C3-IC complexes. This is indicated by the following observations: as having been shown previously by several authors (Klaus $e t$ al., 1980; Groeneveld et al., 1983; Sainte-Marie et al., 1986) and confirmed in this study, soluble proteins that are unable to activate the complements can never localize within lymphoid follicles. Under normal conditions, IC localized in lymphoid follicles are then trapped by FDC. In irradiated mice, however, IC, though localized temporally in residual follicles, disappeared from residual follicles by 24 after injection, the finding indicating that in irradiated mice, localized IC were not effectively trapped by persisting FDC but therefore soon flowed away from residual follicles. The reason why in irradiated mice, IC, or C3-IC, localized in residual 
follicles were not trapped by FDC is not clear. It seems to us that marked depletion of $B$ lymphocytes in residual follicles may be correlated with the ineffectiveness of FDC to bind with localized IC. To support this, the $24 \mathrm{~h}$ follicular localization of injected IC in lymph nodes of irradiated mice was restored in parallel with the residual follicles becoming repopulated with $B$ lymphocytes. If this interpretation is correct, the possibility exists that B lymphocytes in lymph node follicles may play a role in the process of trapping by FDC of localized IC in nomal mice as well as in irradiated animals: one possible role of follicular B lymphocytes could be intrafollicular transport of localied IC to FDC. This point is of interest and awaits further ellucidation.

Alternative explanation for possible ineffectiveness of persisting FDC to trap localized IC in residual follicles is that sublethal irradiation may have directly affected the activity of FDC in lymph node follicles. FDC have been shown to be radio-resistant (Hunter et al., 1969; Brown et al., 1973; Humphrey et al., 1984; Hoshi et al., 1984; Chen et al., 1995). However, It is evident that FDC in lymph node follicles were partly damaged by sublethal irradiation. This is indicated by the finding that after the irradiation, the number of follicles in each popliteal node reduced from 12 to 8 , indicating that smaller follicles and their containing FDC in normal popliteal nodes had been destroyed and vanished due to irradiation. Thus, it is likely that FDC in well developed follicles in normal popliteal node may also have been partly affected by irradiation, and thereby FDC persisting in residual follicles may have become unable effectively to trap localized immune complexes. In this case, repopulation of B lymphocytes in residual follicles may help the recovery of FDC's capacity to trap in vivo -applied IC.

It was previously suggested that macrophages play a part in the transport and trapping of IC in lymphoid follicles (White et al., 1970). The possibility existed that macrophages might participate in the change of trapping and retention of IC in lymph node follicles after irradiation. In this study, therefore, the pattern of distribution of macrophages in, and of their migration from the drained site to, popliteal nodes was compared between normal and irradiated mice. The results showed that there was no noticeable change in the pattern of distribution and migration of macrophages after irradiation. Further, there was no indication that macrophages participated in the follicular localization of IC in normal and irradiated mice.

\section{References}

1) Brown JC, Harris G, Papamichail M, Sljivic VS and Holborow EJ. The localization of aggregated human $\gamma$-globulin in the spleens of normal mice. Immunology 1973; 24:955968.

2) Chen LL, Adams JC and Steinman RM. Anatomy of germinal centers in mouse spleen, with special reference to "follicular dendritic cells". J Cell Biol 1978; 77:148-164.

3) Chen D, Hoshi H, Tanaka K and Murakami G. Postnatal development of lymphoid follicles in the rat Peyer's patches, with special reference to increased follicle number. Arch Histol Cytol 1995; 58:335-343.

4) Dijkstra CD, Van Tilburg NJ and Döpp EA. Ontogenic aspects of immune complex trapping in the spleen and popliteal lymph nodes of the rat. Cell Tissue Res 1982; 223:545-552.

5) Dijkstra CD, te Velde AA and Van Rooijen N. Localization of horseradish peroxidase(HRP)-anti-HRP complexes in cryostat sections: Influence of endotoxin on trapping of immune complexes in the spleen of the rat. Cell Tissue Res 1983; 232:1-7.

6) Gray D, McConnell I, Kumararatne DS, Maclennan ICM, Humphrey $\mathrm{JH}$ and Bazin $\mathrm{H}$. Marginal zone B cells express CR 1 and CR 2 receptors. Eur J Immunol 1984; 14:47-52.

7) Groeneveld PHP, Eikelenboom $P$ and Van Rooijen N. Mechanism of follicular trapping: similarities and differences in trapping of antibody-complexed antigens and carbon particles in the follicles of the spleen. $J$ Reticuloendothel Soc 1983; 33:109-117.

8) Hoshi H, Yoshida K, Kamiya K and Aijima H. Reconstruction of lymph follicles in the mouse popliteal lymph node after X-irradiation damage. Tohoku J Exp Med 1984; 144:165-181.

9) Humphrey JH, Grennan D and Sundaram V. The origin of follicular dendritic cells in the mouse and the mechanism of trapping of immune complexes on them. Eur J Immunol $1984 ; 14: 859-864$.

10) Hunter RL, Wissler RW and Fitch FW. Study on the kinetics and radiation sensitivity of dendritic macrophages. Adv Exp Med Biol 1969; 5:101-111.

11) Kamperdijk EWA, Dijkstra CD and Döpp EA. Transport of immune-complexes form the subcapsular sinus into the lymph node follicle of the rat. Immunobiol 1987; 147:395405.

12) Kinet-Denoël C, Heinen E, Radoux D and Simar LJ. Follicular dendritic cells in lymph nodes after $\mathbf{X}$-irradiation. Int J Radiat Biol 1982; 42:121-130.

13) Klaus GGB and Humphrey JH. The generation of memory cells. I. The role of $\mathrm{C} 3$ in the generation of $\mathrm{B}$ memory cells. Immunology 1977; 33:31-41.

14) Klaus GGB, Humphrey JH, Kunkl A and Dongworth DW. The follicular dendritic cell: its role in antigen presentation in the generation of immunological memory. Immunol Rev 1980; 53:3-28.

15) Kroese FGM, Wubbena AS and Nieuwenhuis P. Germinal center formation and follicular antigen trapping in the spleen of lethally $\mathrm{X}$-irradiated and reconstituted rats. Immunology 1986; 57:99-104.

16) Laman JD, Kors N, Van Rooijen $\mathrm{N}$ and Claassen $\mathrm{E}$. Mechanism of follicular trapping: localization of immune complexes and cell remnants after elimination and repopulation of different spleen cell populations. Immunology 1990; 71:57-62.

17) Nettesheim $P$ and Hanna MG. Radiosensitivity of antigentrapping mechanism and its relation to the suppression of immune response. Adv Exp Med Biol 1969; 5:167-175. 
18) Radoux D, Kinet-Denoël C, Heinen E, Moeremans M, De Mey J and Simar LJ. Retention of immune complexes by Fc receptors on mouse follicular dendritic cells. Scand J Immunol 1985; 21:345-353.

19) Sainte-Marie G and Peng FS. Diffusion of a lymph-carried antigen in the fiber network of the lymph node of the rat. Cell Tissue Res 1986; 245:481-486.

20) Szakal AK, Holmes KL and Tew JG. Transport of immune complexes from the subcapsular sinus to lymph node follicles on the surface of nonphagocytic cell, including cells with dendritic morphology. J Immunol 1983; 131:17141727.

21) Tew JG, Kosco MH and Szakal AK. The alternative antigen pathway. Immunology Today 1989; 10:229-232.

22) Unanue ER. Antigen-presenting function of the macrophage. Annu Rev Immunol 1984; 2:395-428.

23) Van den Berg TK, Döpp EA, Daha MR, Kraal G and Dijkstra CD. Selective inhibition of immune complex trapping by follicular dendritic cells with monoclonal antibodies against rat C3. Eur J Immunol 1992; 22:957-962.

24) Van den Berg TK, Yoshida K and Dijkstra CD. Mechanism of immune complex trapping by follicular dendritic cells.
Cur Top Microbiol Immunol 1995; 201:49-67.

25) Van Rooijen. Mechanism of follicular antigen trapping. Evidence for a two-cell mechanism using double isotope autoradiography. Immunology 1974; 27:617-622.

26) Veerman AJP and Van Rooijen N. Lymphocyte capping and lymphocyte migration as associated events in the in vivo antigen trapping process. An electron microscopic autoradiographic study in the spleen of mice. Cell Tissue Res 1975; 161:211-217.

27) White RG, French VI and Stark JM. A study of the localization of a protein antigen in the chicken spleen and its relation to the formation of germinal centres. J Med Microbiol 1970; 3:65.

28) Yoshida K, Van den Berg TK and Dijkstra CD. Two functionally different follicular dendritic cells in secondary lymphoid follicles of mouse spleen, as revealed by CR1/2 and FcRyll-mediated immune-complex trapping. Immunology 1993; 80:34-39.

29) Yoshida T, Takaya $K$ and Sakamaki A. The relationship between follicular dendritic cells and antigen transporting cells in the rat lymph node during secondary response. Dendritic cells 1994; 4:159-166.

\section{Explanation of Figures}

\section{Plate I}

Fig. 1. Twenty-four-hour localization of subcutaneously administered HRP-anit-HRP immune complexes in lymphoid follicles of the popliteal lymph nodes in irradiated and control mice.

At each time point, three animals were used. The height of the column and vertical bar indicates the mean of the number of follicles per node \pm SD.

Left column indicates the number of follicles displaying definite (densely hatched) and weak (loosely hatched) localization of in vitro -applied immune complexes (IC). Right column indicates the number of follicles displaying definite (darkly closed) and weak (dotted) $24 \mathrm{~h}$ localization or no localization (open) of in vivo -injected immune complexes

Fig. 2. Earlier follicular localization of subcutaneously injected immune complexes in the popliteal lymph nodes of control and irradiated mice.

Explanation, see that of Fig. 1. 
Plate I
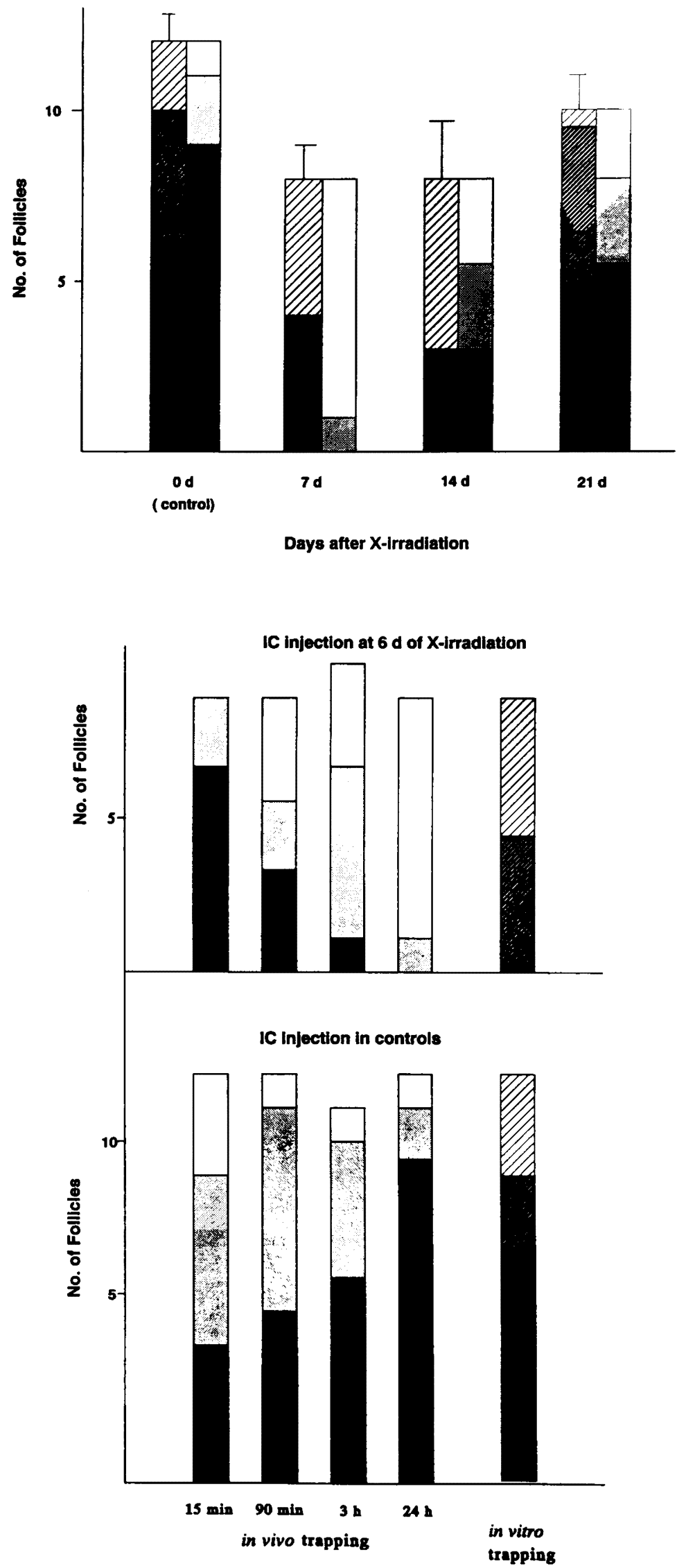


\section{Plate II}

Fig. 3. A popliteal node from a control mouse.

a: cryosection immunostained for B220-positive lymphocytes, showing a fairly well developed lymphoid follicle (primary follicle) in the peripheral cortex.

b and c: cryosections neighboring to section a, showing network of in vitro -trapped immune complexes (b) and $24 \mathrm{~h}$ localization of in vivo -injected immune complexes (c) in a follicle. 

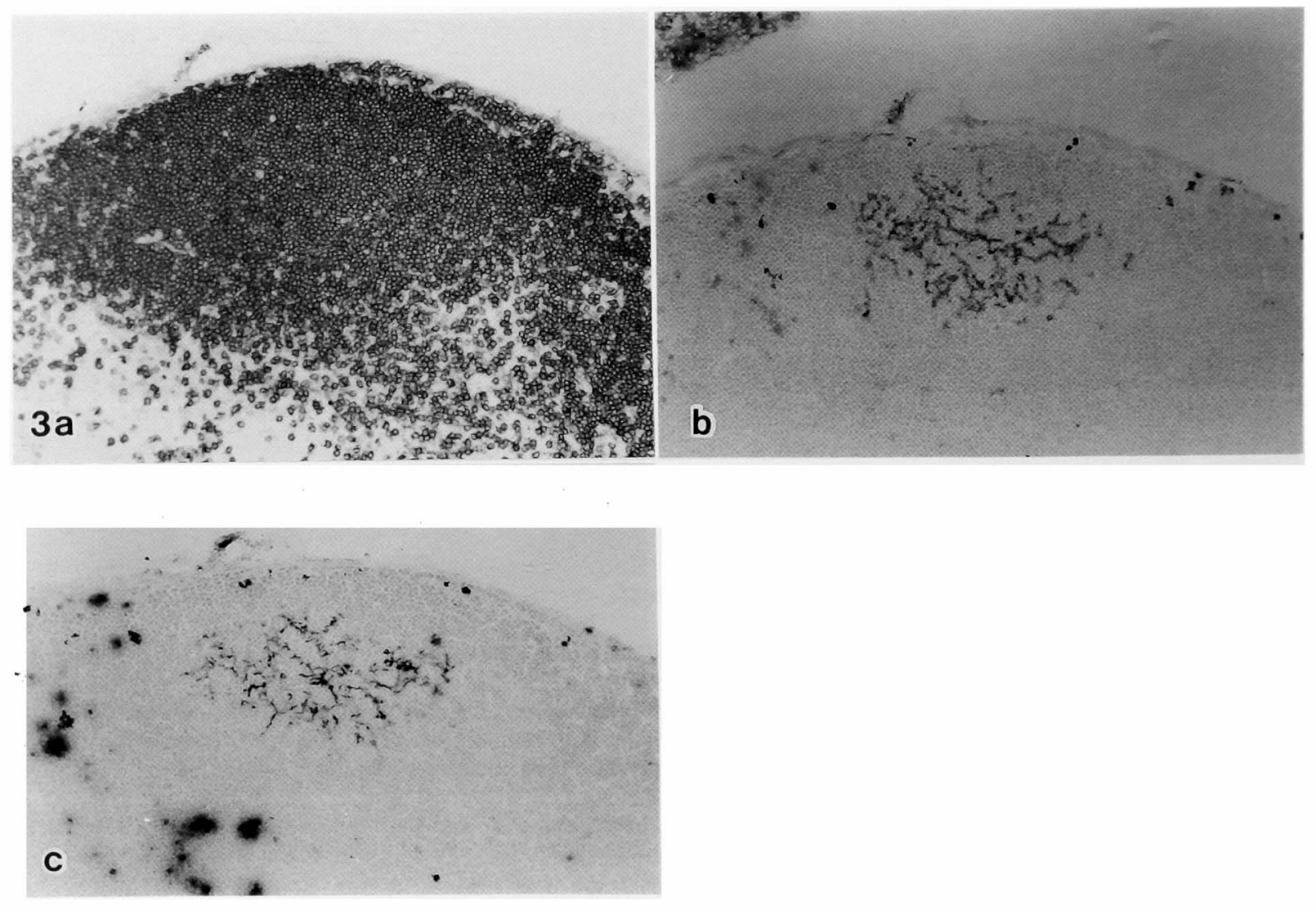


\section{Plate III}

Fig. 4. A popliteal node from an experimental mouse which had been given HRP-anti-HRP immune complexes at 6 days of Xirradiation and killed $24 \mathrm{~h}$ later.

a: cryosection immunostained for B220-positive cells. Two small residual follicles can be seen in the peripheral cortex.

b, c and d: cryosections neighboring to section a, showing localization of in vitro -applied IC (b), network of complement receptors (CR1) (c) and no detectable $24 \mathrm{~h}$ localization of in vivo -injected immune complexes (d) in two residual follicles.

Fig. 5. A popliteal node from an experimental mouse which had been given HRP-anti-HRP complexes at 6 days of X-irradiation and killed 15 min later.

a: cryosection immunostained for B220-positive lymphocytes, showing a small residual follicle in the peripheral cortex.

$\mathrm{b}$ and c: cryosections neighboring to section a, showing network of complement receptors (CR 1) (b) and definite localization of in vivo -injected immune complexes in a residual follicle at $15 \mathrm{~min}$ after injection (c). 

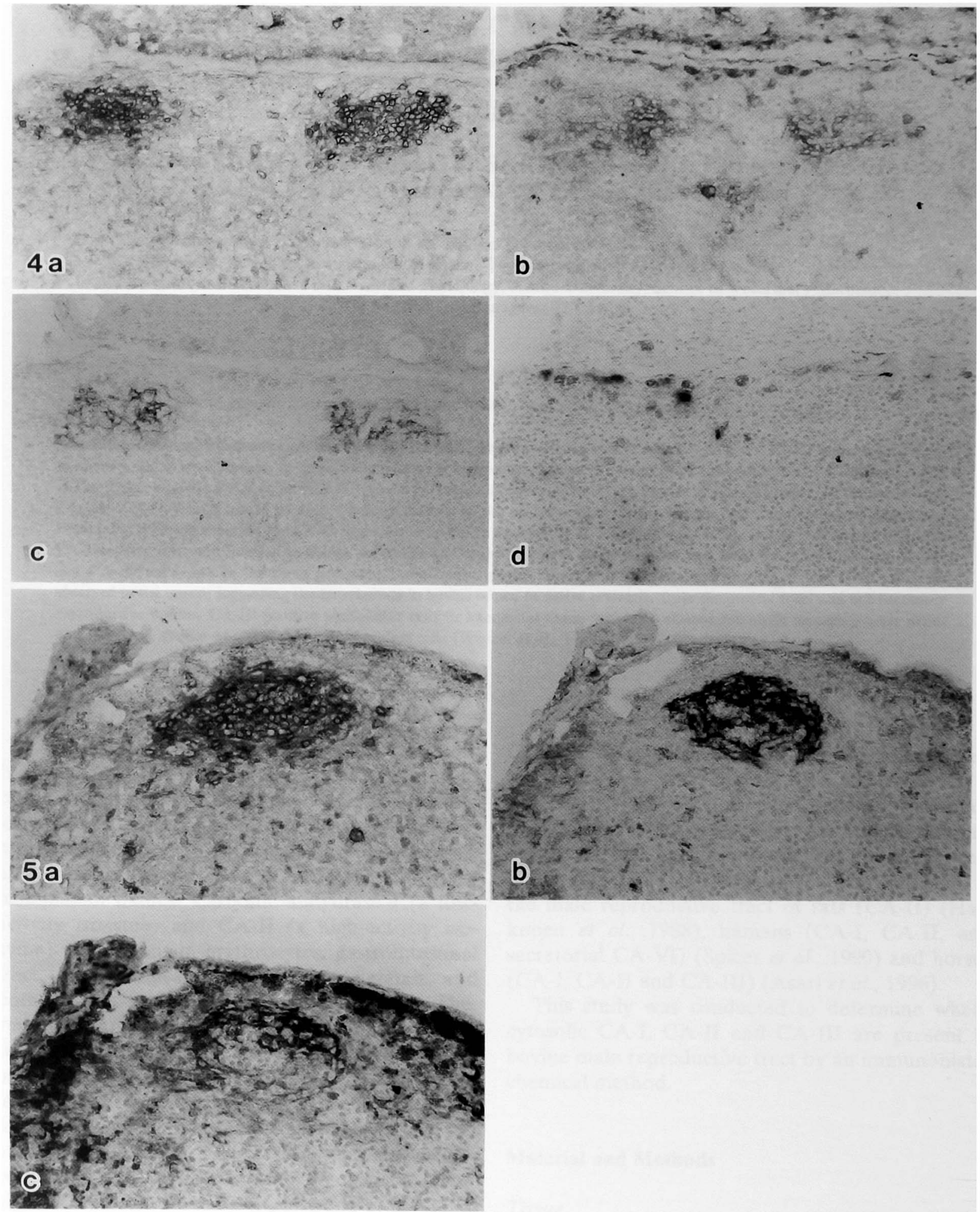